\title{
Exposing Bias through a Deficit Thinking Lens Using Content-Analysis of Macro Level Policies
}

\author{
Dusty L. Palmer ${ }^{1}$ \& Kumudu Witanapatirana ${ }^{2}$
}

1. Corresponding author

Texas Tech University College of Education, Principal Fellows Coach, Lubbock, TX, USA.

E-mail: dusty.palmer@ttu.edu

2. Texas Tech University College of Education, Department of Educational Psychology and Leadership, Lubbock, TX, USA.

\section{Article Info}

Received: March 30, 2020

Revised: April 22, 2020

Accepted: April 22, 2020

\subsection{3/repam.01.02.2}

This is an Open Access article distributed under the terms of the CC BY-NC-ND 4.0 International license.

(https://creativecommons.org/licenses/bync-nd/4.0)

\section{How to cite}

Palmer, D. K. \& Witanapatirana, K. (2020). Exposing bias through a deficit thinking lens using content-analysis of macro level policies. Research in Educational Policy and Management, 2(1), 23-39.

https://doi.org/10.46303/repam.01.02.2

\section{ABSTRACT}

Educational policies can affect students in a negative or positive way depending on the context and interpretation within the policy. Unfortunately, deficit thinking policies exist that prevent all students from receiving equitable learning experiences. This study focuses on a content analysis approach to expose deficit thinking vocabulary or language that maybe embedded at the macro-level of educational policy. The article is intended to make policymakers aware of their own biases when creating policies. The study aims to provide ways to identify and address thinking by examining the vocabulary and language within macro-level policies.

\section{KEYWORDS}

Deficit thinking, educational policy, biases 


\section{INTRODUCTION}

Studies in education reveal decision-making for all students is more effective when it involves all stakeholders, including students, parents, the school, the community, policymakers, and researchers, to provide optimal opportunity to meet the needs of all students. Unfortunately, the concept that all students can learn is a research and rhetoric myth rather than a shared belief. This is largely due to teachers' exposure to negative indoctrination to previous research (Delpit, 1995) that links failure in students' challenges to deficits in families and/or communities (Valencia, 2010; Kennedy \& Soutullo, 2018). Furthermore, Richard Valencia (2010) argues, "deficit thinking is so protean in nature, taking different forms to conform to politically acceptable notions at the moment, and while the popularity of different revisions may change, it never ceases to influence school policy and practice" (p. 7). Systems that do not change for the betterment of all students imply that policies at the macro-level consist of deficit thinking and bias that result in an implicit or explicit trickling down effect that allows for oppression to continue to exist. To address the needs of students in public education, researchers and school policymakers must analyze the content, context, and implications of the policies to identify deficit thinking language, actions, and practices that perpetuate systematic oppression and preclude education's overall objective, the success of all students.

The state of Texas is providing a unique opportunity for school districts to provide flexibility by addressing areas of need through the District of Innovation (DOI) plans. This study specifically examines a random selection of DOI plans. At the time of this study, there were 863 Texas school districts that have approved DOI plans. This study focuses on a content analysis approach to expose deficit thinking vocabulary or language that may be embedded at the macro-level of educational policies. It is important to know that the DOI plans examined in this study were chosen due to the researcher's knowledge of the existence of the documents, experience with the policies and practices provided within the documents, and the convenience of retrieving the documents. The purpose of this qualitative content analysis was to detect if there was any underlying deficit thinking vocabulary and/or language within macro-level policies in general. It is also important to note that deficit thinking is defined in a broad sense and does not indicate that any of the findings are specifically associated with any particular student group. The study aims to provide ways to identify and address deficit thinking by examining the vocabulary and language within macro-level policies. The following question guided this study: In what ways do macro-level policies for Texas public schools reflect deficit thinking vocabulary and/or language?

\section{LITERATURE REVIEW}

The underlying premise of the statement by Fredrick Douglass that introduced this article is still relevant today: freedom from oppression and fairness despite differences are the cornerstone to safety, especially in a public school setting. One effective way to ensure that all classes or 
segments of a population feel safe in providing input is by including all stakeholders in the decision-making process. Including students, parents, the school personnel, community members, policymakers, and researchers in decision-making improves outcomes, as studies have shown. Bringing people together, rather than excluding them in the process, provides opportunities for agreement and an understanding of shared responsibility and accountability. In an article discussing the need for the present accountability systems, Valencia, Valenzuela, Sloan, and Foley (2001), quoting Arthur Pearl, examine the impact of deficit thinking on policies implemented and agree "school failure [and success] can be fully understood only when analyzed in the broadest political, economic, and cultural contexts. Macropolicies establish the boundaries of possibilities" (as cited in Valencia et al., 2001, p. 319).

\section{Deficit Thinking}

Patton Davis and Museus (2019) conducted an analysis of the conceptualizations and definitions of deficit thinking amongst scholarly research and centralized on four themes which include "a blame the victim orientation, a grounding in larger complex systems of oppression, a pervasive and often implicit nature, and effects that reinforce hegemonic systems" (p. 121). Valencia (1997) explained the concept of deficit thinking, in that it is the theory that students fail due to the obstacles they face outside of the school environment. The obstacles include the individual, family, and community (Burton \& Robles-Pina, 2009; Solórzano \& Yosso; 2001; Valencia; 1997). Valencia (1997) described the evolution of deficit thinking and attempts to dismantle the previous notions of why students are failing, by addressing other variations of deficit thinking, such as genetic based models as well as cultural and environmental based models. Burton and Robles-Pina (2009) examined the historical achievement gap between Hispanic and White students and concerns raised by teachers, parents, and society alike. Furthermore, Burton and Robles-Piña (2009) note that Hispanic students are not faring well on standardized tests on the theoretical perspective of cultural thinking or cultural deficit thinking, blaming the student's social, cultural, or economic status as the root cause of failure.

Patton Davis and Museus (2019) found that there are variety of terms that describe deficit thinking such as "deficit framing, deficit paradigm, and deficit perspective" (p. 121). At the conclusion of their analysis, Patton Davis and Museus (2019) provide four implications for future research. The third implication from their study is that researchers need to critique deficit thinking in nature and context of how language is used in narratives that consequently could produce anti-deficit agendas and policies. A review of deficit thinking language is necessary to understand the underlying drivers of developing macro-policies. When creating standards and policies, leaders can only control implicit and explicit bias when evaluating through a deficit thinking lens; therefore, this literature review explores two underlying causes of deficit thinking, implicit and explicit bias.

\section{Implicit and Explicit Bias}


Stakeholders and policymakers alike need to be cognizant of implicit bias and how to identify biases they may not be aware of when developing policies. Staats (2016) stated that implicit bias is also known as unconscious awareness. Greenwald and Krieger (2006) defined implicit bias as "an aspect of the new science of unconscious mental processes that has substantial bearing on discrimination law" (p. 946). Individuals may not know they have an implicit bias; however, some triggers can activate implicit bias. Such triggers may include race, ethnicity, gender, or age, resulting in negative and positive emotions (i.e., attitudes toward an individual) and stereotyping, which ultimately influence one to have an implicit bias (Greenwald \& Krieger, 2006). Ford (2014) argued that underrepresentation of student groups is based on the belief in attitudes that are embedded in deficit paradigms. Deficit thinking is grounded in the idea that "students, particularly of low-SES background and color, fail in school because they and their families have internal defects, or deficits, that thwart the learning process" (Valencia \& Black, 2002, p. 83). Lincona (2013) explored the impact of deficit thinking on students, revealing an example of implicit bias. Lincona (2013) conducted an ethnographic-style case study focusing on the beliefs of teachers about immigrant students that reside close to the U.S.-Mexico border, whether the student was a citizen of Mexico or a citizen of the U.S. In this study, Lincona (2013) found that teachers' deficit lens resulted in the placement of immigrant students into the lower performing classes and the nongifted classes.

Previous research reveals recommendations on how individuals can identify symptoms of implicit biases that they may have. Diversity initiatives in business, education, and organizations reflect a surge of interest; several on-line assessments are available and free of charge. One such instrument is the Implicit Association Test (IAT), which measures the strength of associations between concepts and evaluations/or stereotypes (Projectlmplicit, 2011). Van den Bergh, Denessen, Hornstra, Voeten, \& Holland (2010) used the IAT in their study measuring the prejudiced attitudes of 41 elementary school teachers and found that the ethnic achievement gap differed from classroom to classroom, based on the teacher's expectations. Greenwald and Krieger (2006) implied that the IAT can also be adapted to measure "group-valence and grouptrait associations that underlie attitudes and stereotypes" (p. 952).

Both implicit bias (i.e., unconsciously knowing) and explicit bias (i.e., consciously knowing) can prompt deficit thinking to drive policy. Greenwald and Krieger (2006) stated "a belief is explicit if it is consciously endorsed. An intention to act is conscious if the actor is aware of taking an action for a particular reason" (p. 946). Greenwald and Krieger (2006) reiterated that consciousness drives human behavior. In evaluating equitable school reform, Valencia et al. (2001) stated that there is much literature to support the lack of equal educational opportunities and the implications of research, for "improvement of schooling for minority students have often been disregarded by policymakers and the courts" (p. 319). Scheurich and Skrla (2001) claimed "racial prejudice has changed and is rarely public and overt," but they also stated, "research clearly indicates that children of color do not get an equitable chance to be successful in school" (p. 323). The idea that educators seek to be color blind, therefore treating all children 
equally, was explored, and these researchers concluded, "The evidence strongly indicates that there is systemic bias in schools against children of color" (p. 323). Both arguments, Valencia et al. (2001) and Scheurich and Skrla (2001), lead to suggestions on how to overcome the implicit and explicit bias that exists. Systematic examinations, including data disaggregation or data digs in the form of equity audits, to review biases can deconstruct oppressive systematic actions and expand the asset-driven policymakers' understanding.

\section{Equity Audits}

Evaluating educator biases leads to finding inequities. One key strategy for identifying inequities is conducting equity audits (Skrla, Scheurich, Garcia, and Nolly, 2004) and equity-driven data digs. Staats (2016) suggested to dig for data, specifically discipline data based on referrals by ethnicity, and check to see if the referral warranted subjectivity or objectiveness. Skrla et al. (2004) recommended that school educators start to increase equity by conducting equity audits. Skrla et al. (2004) focused on three areas of the equity audit: teacher quality, educational programming, and student achievement. Within their framework, teacher quality includes checking teacher certifications, teacher experiences, and teacher education levels. The educational programming includes looking at student groups that include special education students, gifted and talented students, bilingual education, and student discipline. The third category, student achievement, includes results from the state achievement tests, ACT results, graduation rates, and dropout rates. Furman (2012) conducted a review of literature on how K12 aspiring school leaders are prepared in practices of social justice leadership, recommending that educational leadership programs reinforce the use of equity audits. Skrla et al. (2004) also recommended that leadership preparation programs teach their students how to use equity audits for improved student and teacher outcomes. In the attempt to put equity into preparation and practice, a Texas Tech University Principal Fellows Residency preparation program has implemented a school-to-university residency partnership. Gabro, Almager, de Leon, Palmer, and Valle (2018) further state that university faculty taught principal interns to conduct and frame school improvement work through an equity audit lens. The identification and support of struggling teachers, advocating for underrepresented student populations, and leading Professional Learning Community learning spaces were the foundational pieces of the principal residents (i.e., principal interns) authentic learning experiences.

\section{Developing Policies}

Policymakers employ formulaic steps in policy making, and value decisions are assumed to be "relatively straightforward" and are "clearly formulated in advance," meaning the problem that the policy seeks to resolve is accepted as an unquestioned, objective fact, and attention is instead focused on identifying solutions to the given problem (Bacchi, 1999, p. 18). The effect of deficit thinking on students is a harsh reality. Scheurich and Skrla (2001) stated that educators are responsible and must address issues when developing policies: "We educators often 
steadfastly resist any honest, open examination of ourselves, our ways of thinking, our assumptions or our methods" (p. 323). School and community stakeholders often form committees to develop strategic goals, action plans, procedures, and policies for the school. There is limited research on analyzing school district policies at the local school level; however, if the reality described above exists then attention needs to be brought by analyzing school policies that may include vocabulary or language that is associated with deficit thinking. There is also limited research how implicit and explicit bias influence school policies and practices within the school. Mintrop, MacLellan, and Quintero (2001) used a content analysis approach to explore school improvement plans (SIPs) for school districts in Maryland, Kentucky, and California. Their study focused on the effects accountability systems have on school improvement by identifying patterns within the SIPs. Absent from the study was the lens of deficit thinking. In searching the databases of google scholar, JSTOR, and EBSCO, other content analysis studies address educational policy at the national level. Roumell and Salajen (2014), for example, studied technology plans as well as higher education college course content analysis conducted by the Educational Policy Improvement Center (2014).

Clycq, Ward Nouwen, \& Vandenbroucke (2014) explored meritocracy and deficit thinking in designing policies in their article published in the British Educational Research Journal and as cited by Bourdieu (1990) as a "sorting mechanism for different subgroups" and that the policies and system favor "those whose home environment, worldviews and habitus correspond most with the system" (p. 797-798). The predominately middle class primarily devises the education system and therefore the policymakers often do not appreciate or accept the varying needs of those with different backgrounds and perceptions.

Deficit thinking reveals an effect on the design, the creation, and implementation of policies. Consequently, implicit and explicit bias of policymakers can limit learning opportunities for students of color, students with a low socio-economic status, and immigrant students. Presumably, implicit bias, or that of unconsciously knowing, could be the underlying reason in developing deficit thinking policies such as the District of Innovation Plan. This study aims to contribute to the content analysis field in Texas education policy exposing bias through a deficit thinking filter to the vocabulary and language of policies. Furthermore, this study aims to reach policymakers on how implicit and explicit bias can impact students of color, low SES students, and immigrant students.

\section{CONCEPTUAL FRAMEWORK}

This study used a conceptual framework embedding Valencia's (2010) six characteristics of deficit thinking within a stakeholders decision-making model. The six characteristics are blaming 
the victim, oppression, pseudoscience, temporal changes, educability, and heterodoxy (Valencia, 2010). Figure 1 below provides a conceptualization of the framework process.

Figure 1: Conceptualization of a Deficit Thinking Structure on School Policies, Procedures, and Plans

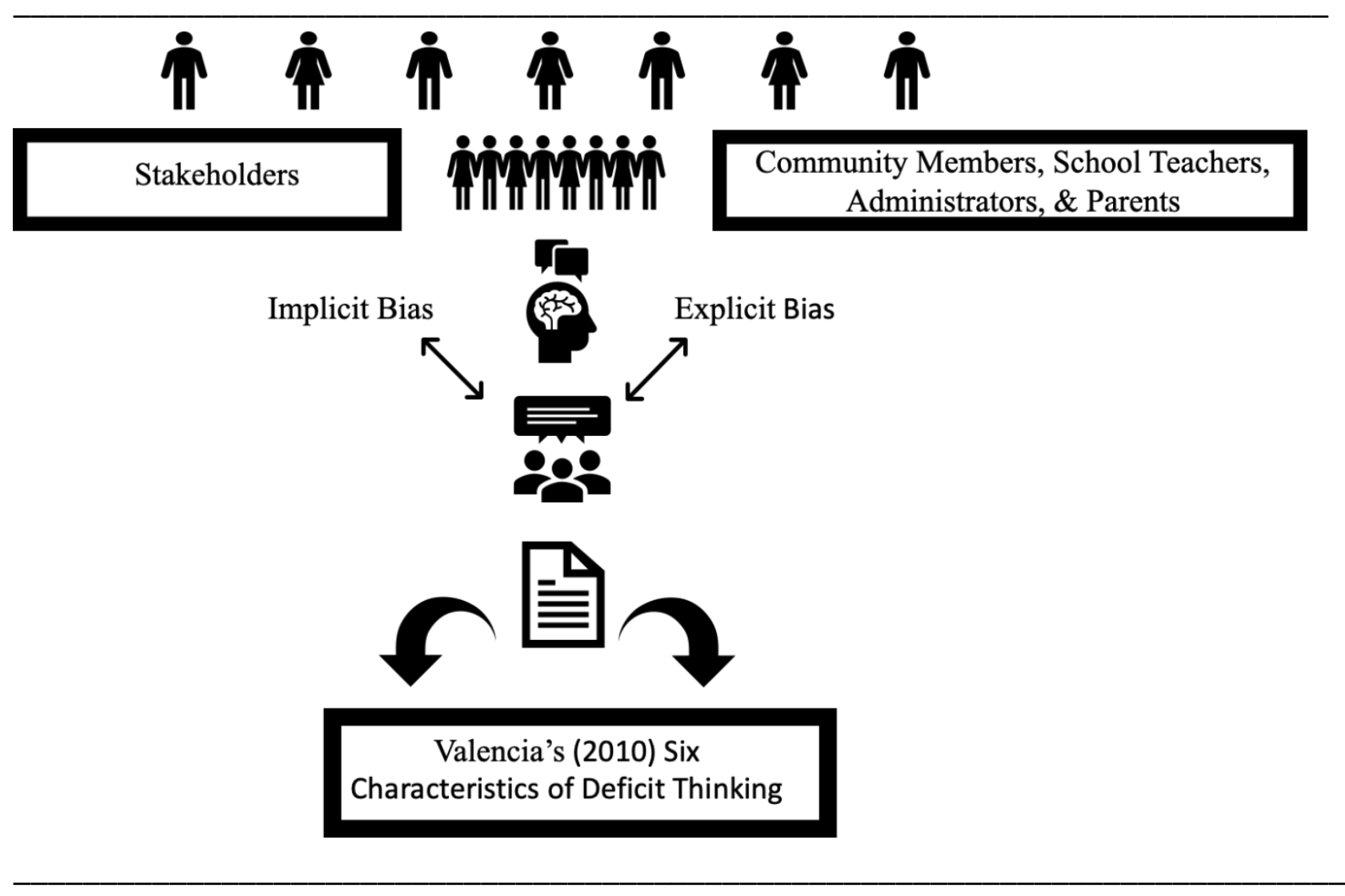

Individuals in a school community have differing opinions, beliefs, and perspectives when making decisions on issues; however, their stakeholders' insights are pertinent in decisionmaking. Often, stakeholders, including community members, teachers, school staff, school administrators, and parents, form to create and/or adjust policies, procedures, and plans for their school. However, making decisions as a collective group does not always occur in a harmoniously way because of the diversity of thought. There are several factors that occur in the decision-making process that can alter the final collective decision. Factors may include a conscious (i.e., explicit bias) or unconscious approach (i.e., implicit bias) that could create a deficit thinking structure (Staats, 2016; Greenwald \& Krieger, 2006). Deficit thinking structures can appear at the macro-level in school district policies that can affect a student at the microlevel.

\section{METHODOLOGY}

The methodology used for this study was a qualitative content analysis design (Krippendorff, 2018) approached through the framework of deficit thinking. Macro-level policies are the focus 
of the content analysis. The documents selected for this study are the DOI plans created by stakeholders of Texas Public Schools and other documents referenced within the DOI. The documents underwent an analysis to determine if any language provided within the plans were associated with deficit thinking. In Texas, there are approximately 1,023 school districts, which include independent school districts and consolidated school districts. During the 84th legislative session in Texas, the legislature established DOI plans for certain independent and consolidated school districts that met eligibility standards. Public school districts that at least met standards on their school district's accountability were eligible to apply. School districts that had improvement required ratings were not eligible. According to Texas Education Code (TEC), the local innovation plan must do the following (TEC Sec. 12A.003):

(1) Provide for a comprehensive educational program for the district, which program may include:

a. Innovation curriculum, instructional methods, and provisions regarding community participation, campus governance, and parental involvement;

b. Modifications to the school day or year;

c. Provisions regarding the district budget and sustainable program funding;

d. Accountability and assessment measures that exceed the requirements of state and federal law; and

e. And any other innovations prescribed by the board of trustees; and

(2) Identify requirements imposed by this code that inhibit the goals of the plan and from which the district should be exempted on adoption of the plan.

The documents of DOI plans were chosen for examination as a result of their accessibility, as they were easily retrieved from the Texas Education Agency (TEA) website. The TEA website provides all the names of the school districts with a direct hyperlink to the district innovation plan created by district stakeholders. The school district's school board approves or rejects the DOI plan created by their stakeholders. The local school board adopts the local DOI plan and then submits it to TEA. TEA then reviews the district's plan to ensure compliance with legal requirements established by the Texas legislature. Keep in mind that the creation of the innovation plan is a team effort rather than one individual. TEA only houses the information and does not authorize or reject the plans. School districts that do not have local innovation plans can create, adopt, and submit. At the time of this study, there were 863 DOls that were submitted to TEA.

\section{Sample}

An initial study was conducted using a random sample of the entire population. To create a sample from the population (N) of 863 school districts, the TEA geographic classification of 
schools were the categories that include major suburban, independent town, major urban, nonmetropolitan fast-growing, non-metro stable, other central city, other central suburban, and rural. Other categories not used in this study were charter schools and a category defined as NA. The researchers randomized the schools within the categories using the (=Rand) function in an Excel worksheet. An application of a $10 \%$ rule identified schools from each category to determine every (nth) school for selection (Creswell, 2017). The researchers used this stratified random selection process to eliminate any bias or subjectivity. As a result of randomizing schools within each category then applying the $10 \%$ rule, 61 schools became the sample size.

This initial sample set revealed findings that were shocking to us. Therefore, we continued to analyze all 863 DOI plans. Out of the 863 plans, 850 plans were accessible for analysis.

\section{Coding Structure}

The next step in the data collection was to create codes based on the deficit thinking model. The codes used were based on Valencia's (2010) six characteristics of deficit thinking: blaming the victim, oppression, pseudoscience, temporal changes, educability, and heterodoxy. Kennedy and Soutullo (2018) used this coding system in a qualitative study examining the perceptions of 29 educators and nine students on how deficit thinking shaped the educational experiences lived by students who were placed in an alternative setting. Since our study focused on content only and not interviews or surveys, member checking did not occur.

\section{Data Collection and Analysis}

The randomly selected DOI plans were gathered from the TEA website and analyzed through the NVivo Qualitative software platform. As mentioned previously, the categories that TEA created for each school district were sorted through NVivo. At first, all 61 selected plans were examined to see if any words or phrases triggered any potential deficit thinking as perceived by the researcher's understanding of the deficit thinking model. After previewing the plans, word queries were conducted to provide frequencies of potential deficit thinking words or phrases that appeared through the readings. Examples of words searched: work habits, these students, those students, and ready to learn. Other items considered during the analysis of the plans were the consideration of limitations for students. For example, some school districts were proposing opportunities for credit recovery or other types of online educational programs for students to complete on their own time outside of the school environment but did not specifically address the reality that not all students would be able to participate in the proposed opportunity. In other words, the researchers were assessing the viability of the online platforms ensuring all students are afforded the same access to the Internet to complete online coursework from their home. After the initial analysis was conducted for the 61 selected school districts, we decided to proceed in analyzing all 863 school districts. Due to technical errors and DOI plans that did not exist on schools' websites, the total number of DOI plans that was analyzed was 850 . 
Additionally, a snowball effect occurred while the researchers examined the DOI plans. For example, sometimes the DOI plans referred to specific sections of the TEC or specific sections from the districts' school board policy online. From this analysis, the specific sections identified as having deficit thinking language were examined allowing for identification of alignment. For example, did the DOI vocabulary or language match the vocabulary or language of the TEC or school board policy?

\section{RESULTS}

The study of the 850 schools yielded impactful results from only analyzing the content and not by examining the attitudes or beliefs from the stakeholders or lawmakers that created the plans, TECs, and the school board policies. However, by analyzing the content in relationship to Valencia's six characteristics of deficit thinking, there is an argument posed that deficit thinking does exist within some of the macro-level district policies.

Table 1 provides evidence of deficit thinking found through analyzing the data. The evidence revealed four deficit thinking discoveries.

Table 1: Macro-Level Policy Coding System

\begin{tabular}{cll}
\hline Code* & Definition* & \multicolumn{1}{c}{ Evidence Found in DOI } \\
\hline $\begin{array}{c}\text { Person-Centered } \\
\text { Attribution }\end{array}$ & $\begin{array}{l}\text { Mentioning of } \\
\text { cognitive and }\end{array}$ & When students are disruptive and/or excessively \\
absent, our teachers must spend time correcting the
\end{tabular}




\begin{tabular}{|c|c|c|}
\hline $\begin{array}{c}\text { Blaming the } \\
\text { Victim }\end{array}$ & $\begin{array}{l}\text { motivational } \\
\text { deficits in } \\
\text { students. }\end{array}$ & $\begin{array}{l}\text { behavior, catching those students up, and cannot } \\
\text { adequately prepare the students who are behaving and } \\
\text { want to learn. These teachers are hampered in their } \\
\text { ability to have the time they need to implement any } \\
\text { kind of truly innovative strategies, because they are } \\
\text { spending their time disciplining students and catching } \\
\text { up students who are falling behind the } 90 \% \text { state } \\
\text { requirement.** } 6 \text { of } 850\end{array}$ \\
\hline Oppression & $\begin{array}{l}\text { Deficit thinking } \\
\text { played out } \\
\text { through } \\
\text { institutional } \\
\text { policies and } \\
\text { practices that } \\
\text { disadvantage a } \\
\text { student group }\end{array}$ & $\begin{array}{l}\text { Students who engage in the kind of misbehavior } \\
\text { described in the transfer agreement and students who } \\
\text { do not attend school for } 90 \% \text { (state requirement) of all } \\
\text { classes interfere with our school district's ability to } \\
\text { educate our student body in a way that is effective, } \\
\text { tailored to students who are at school consistently and } \\
\text { ready to learn, and able to focus time and attention on } \\
\text { preparing for work towards achievement on state } \\
\text { assessments. }\end{array}$ \\
\hline $\begin{array}{l}\text { Cultural and } \\
\text { Accumulated } \\
\text { Environmental } \\
\text { Deficits } \\
\text { Temporal } \\
\text { Changes }\end{array}$ & $\begin{array}{l}\text { Attributing } \\
\text { students' } \\
\text { challenges to } \\
\text { deficits in } \\
\text { families or } \\
\text { communities }\end{array}$ & $\begin{array}{l}\text { Examine different formats and instructional strategies, } \\
\text { such as online coursework, blended coursework, dual } \\
\text { enrollment, early college, performance tasks, } \\
\text { community-based learning, independent study, } \\
\text { mentorships, and credit recovery for optimum student } \\
\text { engagement. } \\
7 \text { of } 850\end{array}$ \\
\hline Educability & $\begin{array}{l}\text { Suggestions } \\
\text { that students } \\
\text { cannot learn or } \\
\text { improve, or } \\
\text { that if they do } \\
\text { it will be } \\
\text { because of an } \\
\text { intervention } \\
\text { has changed } \\
\text { the student to } \\
\text { be more } \\
\text { "normal" }\end{array}$ & $\begin{array}{l}\text { In approving transfer requests, the availability of space } \\
\text { and instructional staff, availability of programs and } \\
\text { services, the student's disciplinary history records, work } \\
\text { habits, and attendance records are considered. }\end{array}$ \\
\hline
\end{tabular}

* Codes and definitions are replicated by Kennedy and Soutullo (2018).

** Evidence found from the same school district local innovation plan.

\section{DISCUSSION}

The first discovery addresses victim-blaming. There was only one piece of evidence identified through victim-blaming; however, the rationale statement was alarming. The focus of victim- 
blaming was to identify any words that may blame the student. The phrase identified was those students. As described in Table 1, the narrative of the texts refers to the transfer innovative strategy, which is also relevant to the fourth discovery. The rationale for the transfer innovation strategy from one school district reads:

When students are disruptive and/or excessively absent, our teachers must time correcting the behavior, catching those students up, and cannot adequately prepare the students who are behaving and want to learn. These teachers are hampered in their ability to have the time they need to implement any kind of truly innovative strategies, because they are spending their time disciplining students and catching up students who are falling behind the $90 \%$ state requirement.

When blaming the victim occurs, it may lead to oppression where the student is limited to opportunities from the adoption of harmful strategies (Anderson, 2013). The second part of the rationale from above addresses oppression, and it reads as follows:

Students who engage in the kind of misbehavior described in the transfer agreement and students who do not attend school for $90 \%$ (state requirement) of all classes interfere with our school district's ability to educate our student body in a way that is effective, tailored to students who are at school consistently and ready to learn, and able to focus time and attention on preparing for work towards achievement on state assessments.

The notion that students are not ready to learn prompts decision-makers to limit opportunities for the student by rejecting the transfer status at any time during the year, sending the student to another educational setting, or possibly influencing the student to drop out of school.

The third discovery addressed temporal changes. The finding is vague and needs clarification from the stakeholders who wrote the strategy. However, the statement does pose an argument for deficit thinking if students lack resources outside the school environment. As mentioned above and in Table 1, online coursework can be deficit thinking if the student does not have the Internet available in the home environment. Districts may identify students without resources in the home environment and make sure they have access to resources with not only district-funded technology, but district-funded access to the Internet while working at home. On the other hand, districts may provide opportunities for students to use the school after-hours and use the district's Internet and technology; however, this is considered deficit thinking if the student must arrange to come up to the school. A student that is working after school to provide for his or her family, but still wants to complete coursework such as dual credit courses at home and cannot work on the coursework until late at night or early in the morning causes the student to become deprived of the opportunity the districts thinks it is affording. Again, this discovery is vague and needs clarification before deficit thinking can be associated with the innovative strategy.

The fourth discovery was associated with educability. Even though there was only one piece of evidence found for educability, the same finding occurred in 98 out of the 850 school 
districts. The innovation strategy is an exemption from TEC Sec 25.036 and the school board policy online FDA (local), whereas the TEC, Sec 25.036 states,

Any child, other than a high school graduate, who is younger than 21 years of age and eligible for enrollment on September 1 of any school year may transfer annually from the child's school district of residence to another district in this state if both the receiving district and the applicant parent or guardian or person having lawful control of the child jointly approve and timely agree in writing to the transfer.

Furthermore, the FDA (local) school board policy from seven school districts falls under the statute of TEC, Sec 25.036 but more specifically states:

- A nonresident student wishing to transfer into the District shall file an application for transfer each school year with the Superintendent or designee. Transfers shall be granted for one regular school year at a time.

- In approving transfers, the Superintendent or designee shall consider availability of space and instructional staff and the student's disciplinary history and attendance records.

- A transfer student shall be notified in the written transfer agreement that he or she must follow all rules and regulations of the District. Violation of the terms of the agreement may result in a transfer request not being approved the following year.

In other words, the exemption allows for school districts to dismiss a transfer student anytime during the school year based on the criteria described in the FDA (local) policy (i.e., the second bullet point). However, one interesting point is that the DOI has provided more specific criteria as it states:

(Name of School District) ISD maintains a transfer policy under FDA (Local) requiring nonresident students wishing to transfer to file a transfer application each school year. In approving transfer requests, the availability of space and instructional staff, availability of programs and services, the student's disciplinary history records, work habits, and attendance records are considered.

Considering the vocabulary and language of the DOI plans, the researchers questioned if the DOI vocabulary or language in this section is even in compliance with the adopted FDA (local) school board policy and the TEC. Furthermore, the finding of the FDA (local) language using the word work habits registered 98 times out of the 850 school districts. Valencia (2010) implied that subjective language such as the phrase work habits is subject to deficit thinking. Also, keep in mind that stakeholders, who include teachers, staff, administrators, and community members, developed the plan and then the school board approved and adopted the DOI whereas TEA did not authorize or reject any local innovation plans.

Furthermore, there is another statistic that is associated with all seven schools that adopted the FDA (local) policy that used the specific language of work habits. Skrla et al. (2004) pointed out that equity audits are valuable to identify inequities that may exist, and she and her colleagues addressed three main areas to focus on: teacher quality, programmatic evaluation, 
and student achievement. The researchers took further steps in conducting an equity audit as Gabro et al. (2018) elaborated on and found that, in all seven school districts in the pilot study that adopted the FDA (local) policy as described above on student and teacher demographics, the numbers within the school district's Texas Academic Performance Report revealed an average of $88 \%$ teachers were reported as white. The average percent of Hispanic students was $19 \%$, and of African American students was 13\%. Teachers reported as Hispanic were $4.6 \%$, and African American teachers reported at an average of $4 \%$. The demographic statistics reported from the equity audits led the researchers to two further questions. Have there been any transfer removals that are justified by the DOI that revoked any students, but more specifically minority students, from the consideration of work habits? What was the race and ethnicity of the DOI committee members compared to the race and ethnicity of the school district?

\section{RECOMMENDATIONS}

Several recommendations arose from this study. The first recommendation is that all stakeholders developing policies, practices, or procedures at the macro-level should consider conducting an in-depth analysis of the language used within the document. Words and phrases may have different interpretations and may also have varying contextual definitions. However, if the language is not clear and concise, then the readers (e.g., parents) may not even bother pursuing it. For example, a parent that reads the innovation strategy presented in this study that students may complete online coursework on their own time may not even bother to pursue this opportunity because their student does not have Internet at home and is working two jobs to support the family, and therefore, cannot make it to open-school night to use the computer and/or Internet. The second recommendation is that macro-level policies use objective language to limit the possibility of bias, either implicit or explicit, that allows for the trickle-down effect to the micro-level (i.e., the students affected by the macro-level policy). Reading the language in the policies alone did reveal deficit thinking; however, this study suggests the need for follow-up interviews providing clarification and interpretation. Another recommendation is for policymakers to adhere to legal statutes such as the Texas Education Code that outweigh local policy such as District of Innovation Plans. Further recommendations include a matrix or rubric similarly based on Valencia's (2010) six characteristics be used as stakeholders are developing and writing macro-level policies that affect students at the micro-level.

\section{CONCLUSION}

The impact of deficit thinking policies is devastating when considering how many schools and students it can affect. In the 2017-2018 school year, Texas consisted of 1,023 public school districts and approximately 5.3 million early education students to 12 th-grade students. Today school districts continue to create and submit DOI plans to TEA, and it is imperative that school district's policymakers take into consideration any deficit vocabulary and/or language that exist. 
More importantly, it is critical that policymakers reflect on their own biases, implicit or explicit, when creating policies. This study aims to notify policymakers that biases exist when creating policies.

The study only included $98 \%$ of the total number of school districts that submitted to TEA on having an approved DOI plan. Out of the $98 \%$ reporting school districts, there were significant findings. The next step would be to interview randomly selected stakeholders concerning attitudes and beliefs based on Valencia's (2010) six characteristics. However, if the findings in this study are accurate and the DOls as presently structured do cause at least one student from the entire population of all students in all 863 reporting school districts to face deficit thinking, then the system is failing. All students can learn if provided equitable learning opportunities. If one student is not afforded the same learning opportunities as others then all students is not all students.

\section{REFERENCES}

Anderson, A. (2013). Teach for America and the dangers of deficit thinking. Critical Education, $4(11)$.

Bacchi, C. L. (1999). Women, policy and politics: The construction of policy problems. Sage.

Bruton, A., \& Robles-Piña, R. A. (2009). Deficit thinking and Hispanic student achievement: Scientific information resources. Problems of Education in the 21st Century, 15, 41-48.

Clycq, N., Ward Nouwen, M. A., \& Vandenbroucke, A. (2014). Meritocracy, deficit thinkingand the invisibility of the system: Discourses on educational success and failure. BritishEducational Research Journal, 40(5), 796-819.

Creswell, J. W., \& Creswell, J. D. (2017). Research design: Qualitative, quantitative, and mixed methods approaches. Sage.

Delpit, L. (1995). Other people's children: Cultural conflict in the classroom. Harvard Educational Review, 65, 510.

Douglass, F. (2012). In the words of Frederick Douglas: Quotations from liberty's champion. Cornell University Press.

Education Policy Improvement Center. (2014). National Assessment of Educational Progress Grade 12 Preparedness Research College Course Content Analysis Study. ERIC Clearinghouse.

Ford, D. Y. (2014). Segregation and the underrepresentation of Blacks and Hispanics in gifted education: Social inequality and deficit paradigms. Roeper Review, 36(3), 143-154.

Furman, G. (2012). Social justice leadership as praxis: Developing capacities through preparation programs. Educational Administration Quarterly, 48(2), 191-229.

Gabro, C., Almager, I., de Leon, V., Palmer, D. L., \& Valle, F. (2018). A partnership approach to creating principal pipelines for schools. National Journal of Middle-Grades Reform, $1(1), 9-13$. 
Greenwald, A. G., \& Krieger, L. H. (2006). Implicit bias: Scientific foundations. California Law Review, 94(4), 945-967.

Kennedy, B. L., \& Soutullo, O. (2018). "We can't fix that": Deficit thinking and the exoneration of educator responsibility for teaching students placed at a disciplinary alternative school. Journal of At-Risk Issues, 21(1), 11-23.

Krippendorff, K. (2018). Content analysis: An introduction to its methodology. Sage.

Licona, M. M. (2013). Mexican and Mexican-American children's funds of knowledge as interventions into deficit thinking: Opportunities for praxis in science education. Cultural Studies of Science Education, 8(4), 859-872.

Mintrop, H., MacLellan, A. M., \& Quintero, M. F. (2001). School improvement in schools on probation: A comparative content analysis across three accountability systems. Educational Administration Quarterly, 37(2), 197-218.

Patton Davis, L., \& Museus, S. (2019). What Is Deficit Thinking? An Analysis of Conceptualizations of Deficit Thinking and Implications for Scholarly Research. Currents, 1(1), 117-130.

ProjectImplicit. (2011). Retrieved from https://implicit.harvard.edu/implicit/iatdetails.html Roumell, E. A., \& Salajan, F. D. (2014). The evolution of U.S. e-learning policy: A content analysis of the national education technology plans. Educational Policy, 30(2), 365397.

Scheurich, J. J., \& Skrla, L. (2001). Continuing the conversation on equity and accountability: Listening appreciatively, responding responsibly. Phi Delta Kappan, 83(4), 322-326.

Skrla, L., Scheurich, J. L., Garcia, J., \& Nolly, G. (2004). Equity audits: A practical leadership tool for developing equitable and excellent schools. Educational Administration Quarterly 40(1), 133-161.

Staats, C. (2016). Understanding implicit bias: What educators should know. American Educator, 39(4), 29.

Solórzano, D. G., \& Yosso, T. J. (2001). From racial stereotyping and deficit discourse toward a critical race theory in teacher education. Multicultural Education, 9(1), 2-8.

Texas Education Code. (TEC). Sec.12A.003. Local Innovation Plan. 19 June 2015.

Texas Education Code. (TEC). Sec. 25.036. Transfer of Student. 30 May 1995.

Valencia, R. R. (2010). Dismantling contemporary deficit thinking: Educational thought and practice. Routledge.

Valencia, R. R., \& Black, M. S. (2002). "Mexican Americans don't value education!" On the basis of the myth, mythmaking, and debunking. Journal of Latinos and Education, 1(2), 81103.

Valencia, R. R., Valenzuela, A., Sloan, K., \& Foley, D. E. (2001). Let's treat the cause, not the symptoms: Equity and accountability in Texas revisited. Phi Delta Kappan, 83(4), 318326. 
Van den Bergh, L., Denessen, E., Hornstra, L., Voeten, M., \& Holland, R. W. (2010). The implicit prejudiced attitudes of teachers: Relations to teacher expectations and the ethnic achievement gap. American Educational Research Journal, 47(2), 497-527. 